\title{
Design of Six Legged Spider Robot and Evolving Walking Algorithms
}

\author{
Tolga Karakurt, Akif Durdu, and Nihat Yilmaz
}

\begin{abstract}
In this paper, the development of a legged robot which have needed features for search and rescue operations to access to survivors is aimed. Different walking algorithms are designed for this purpose and tested their performance. Six-legged walking robot is affected by environmental conditions thus encountered conditions are minimized. Additionally, the search team which is exposed to the risk of accidents is reduced and more detailed. The investigation about the possibility of problems such as accident, battery life is largely scaled. Control of robot is provided via communications port on computer. The legged robot inspired by spider is developed with the control mechanism and executes various walking behavior. The effectiveness of the robot is measured according to the performance on rough terrain through six legs. Functional algorithms are built for flexible motion against different conditions such as rough terrain, pit. In the same time, the algorithms moving at various speeds related to structure of legs are presented. The robot used in the project is called as TKSPIDER1 which has three servo motors in each leg.
\end{abstract}

Index Terms-Spider robots, mobile robots, Hekxapod, search and rescue.

\section{INTRODUCTION}

Important developments have been occurred in the history of science and technology. Among them, the concept and applications of robots with each passing year are a larger place. Speed and economic advantages in daily life and industrial applications have increased the use of robots day by day. The robot is an electromechanical system which is capable of autonomous or preprogrammed tasks. Robots independently can also operate under the control of a computer program such as can be directly operated by operator.

Six-legged robots can be used as search and rescue robots, space robots and discover robots. In these fields, hexapod robots present opportunities as having small size and practical mobility. When viewed from this perspective, six-legged walking robot can be easily scroll by produced algorithms in all types of terrain is an advantage. The acceptable number of legs and the ability to move provide more controlled balance to the robot when compared to the majority of multi-legged robots.

RHEX robot is the best known in multi legged robots [1].

Manuscript received September 15, 2014; revised December 9, 2014 This work was supported in part by the Selcuk University under project BAP-14701684.

The authors are with the Department of Electrical and Electronics Engineering, Selcuk University, 42075, Konya, Turkey (tel.: +90-332-223-3726; fax: +90-332-241-0635; e-mail: tolgakarakurt@gmail.com, nyilmaz@selcuk.edu.tr).
RHEX is high performance six legged robot that does not include more complicated mechanism in structure (see Fig. 1). Lauron III was built by FZI (Forschungszentrum Informatik). Each leg of the robot has three degrees of freedom and provided with a three-axis force sensor. The robot contains 12 actuators which each has a current sensor that can be used to detect forces opposing to its movement as shown in Fig. 2 [2]. Also Genghis robot was designed by MIT(Massachusets Institute of Technology) and each leg of the Genghis robot has 1 degree of freedom(DOF), the control of system was performed with totally 6 motor, as shown in Fig. 3. TKSPIDER1 is also shown in Fig. 4.

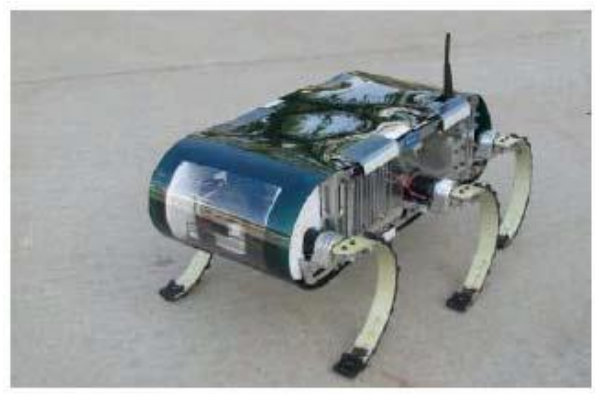

Fig. 1. Rhex [1].

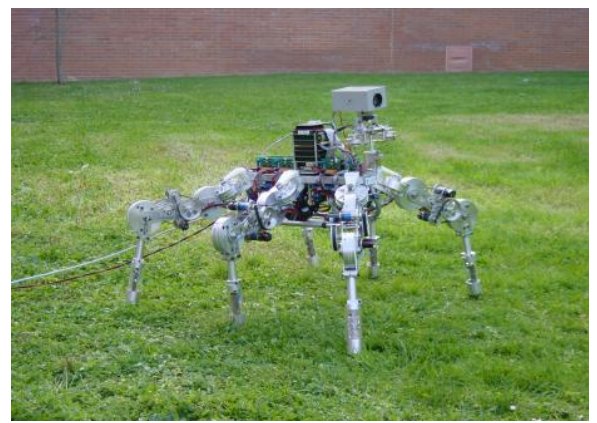

Fig. 2. LauronIII [2].

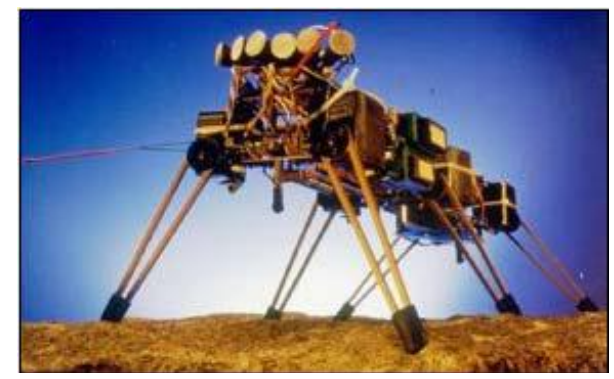

Fig. 3. Genghis [3].

Mobile robots should be efficient about their power resources and high performance. Also for this purpose, weight of the materials used in the structure and control elements should be considered. Use the minimum number of actuator and suitable mechanism design may be a few of them. On the 
other hand, walking algorithms have been developed for functional and flexibility control of robot. Thus, robot can be adapted to the environmental conditions in encountered cases and be able to proceed without stopping to the target. Without being trapped in a certain limit to be able to move more easily is one of basic steps to achieve to main purpose. In this case, needed the velocity is obtained via walking algorithms due to the velocity of robot may vary according to gaits.

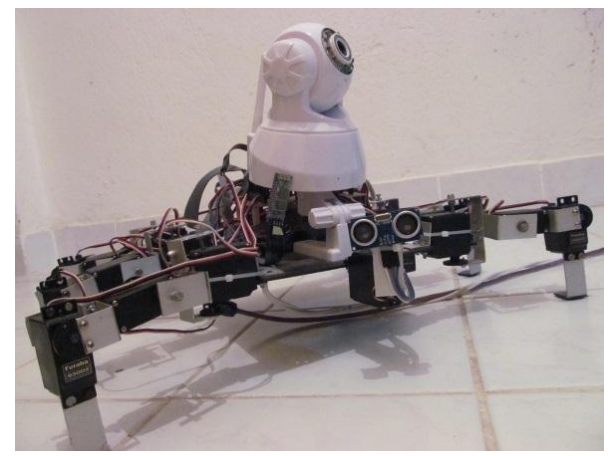

Fig. 4. TKSPIDER1.

\section{DESIGN OF Robot}

TKSPIDER1's mechanical structure was comprised rigid material and symmetrically arranged similar six legs [4].

\section{A. Body}

One-piece that constituting the main body is lightweight composite materials. It is comfortable and cost material in terms of processability. Dimensions of robots are $26 \mathrm{~cm}$ long, $16 \mathrm{~cm}$ wide and $0.3 \mathrm{~cm}$ thick. The legs are fixed at opposite points to the body to keep center on gravity at midpoint of body. As this is important, while moving, robot had continuously balance itself. Ultrasonic sensor, the battery and the power switch is embedded to the front of body and two control circuits, camera and bluetooth module to left portion. Body layout is shown in Fig. 5.

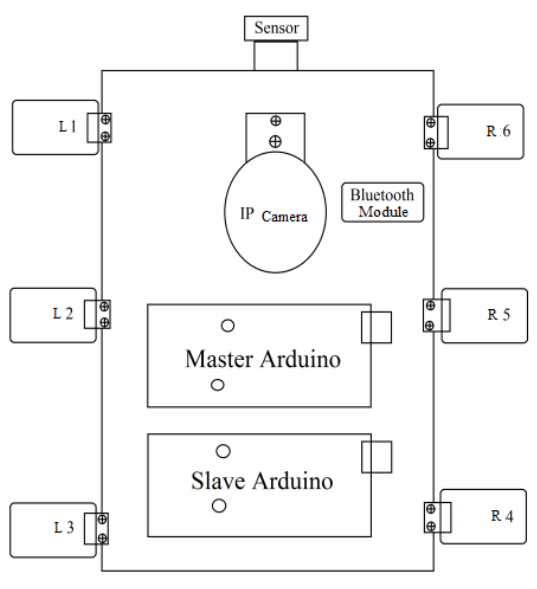

Fig. 5. TKSPIDER1.

\section{B. Legs}

Each leg of the robot has the same mechanical system and three degrees of freedom (DOF). The legs of the robot, in order to realize all-terrain walking algorithms were designed in the same type[5]. Movement axes of one of its legs are as shown in Fig. 6.

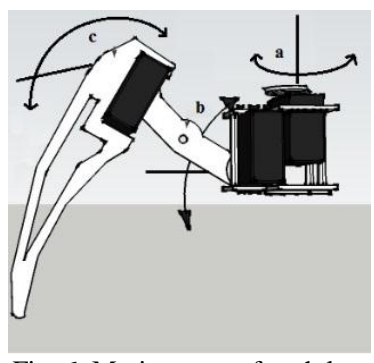

Fig. 6. Motion axes of each leg.

To basic and fast control the system, complicated algorithms and design were avoided. The only difference among similar legs is motion algorithm. Thus, the unbalanced energy consumption and slow to act have been prevented. By this method more stable and efficient performance were obtained. TKSPIDER1's the leg portions which are coxa, femur and tibia are as shown in Fig. 7. Dimensions of leg portions listed in Table I.

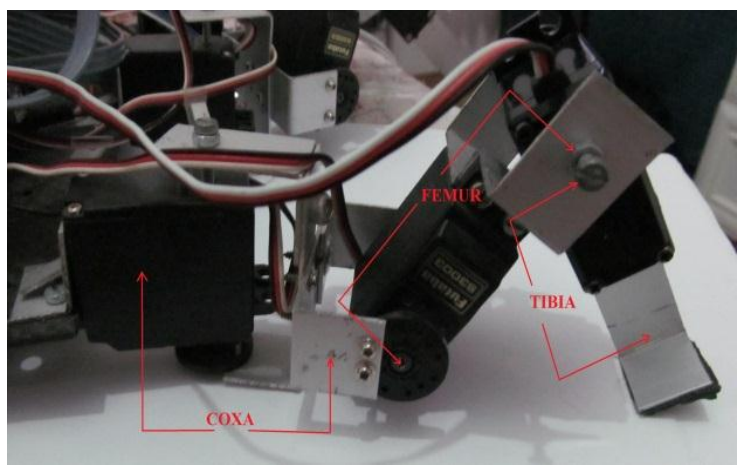

Fig. 7. The leg segments.

TABLE I: DIMENSIONS OF COXA, FEMUR AND TIBIA

\begin{tabular}{|c|c|c|c|}
\hline \multirow[b]{2}{*}{ Segment of Leg } & \multirow[b]{2}{*}{ Length $\mathrm{cm}$} & \multicolumn{2}{|c|}{ Dimensions } \\
\hline & & Width $\mathrm{cm}$ & Thick cm \\
\hline Coxa & 7.5 & 3.5 & 7.0 \\
\hline Femur & 6.5 & 6.5 & 3.0 \\
\hline Tibia & 8.5 & 4.5 & 3.0 \\
\hline
\end{tabular}

\section{Ultrasonic Sensor}

An ultrasonic sensor was used to detect obstacles while moving. Taking samples are transferred to the control board through actuators which may be rotated in certain angles and then has decided to move unimpeded route.

In ultrasonic sensor model, calculated distance value that depending on the acoustic wave motion is utilized [6]. Detailed information about ultrasonic sensor is available in [7]. In this project, any barriers were detected provided by emitting acoustic wave using ultrasonic sensor (Fig. 8).

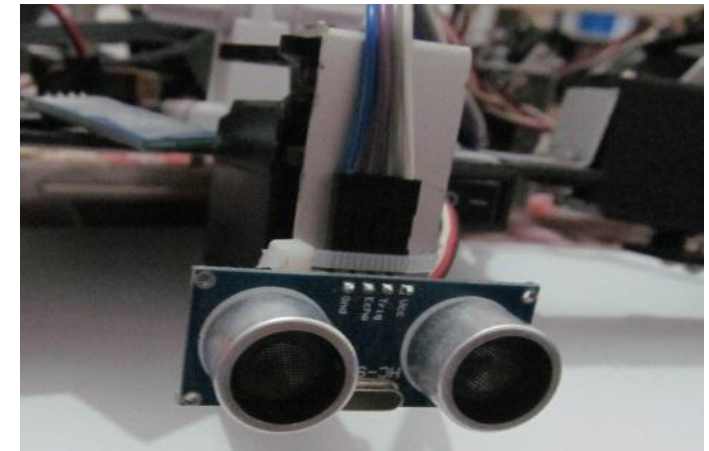

Fig. 8. Ultrasonic sensor was placed on the front of robot to detect any obstacle. 


\section{Overall Structure}

During operation TKSPIDER 1 covered field is $46 \mathrm{~cm} \times 35$ $\mathrm{cm}$. Height of robot body is $5 \mathrm{~cm}$ from ground and the height of the top of robot is $26 \mathrm{~cm}$. General appearance is as shown in Fig. 9.

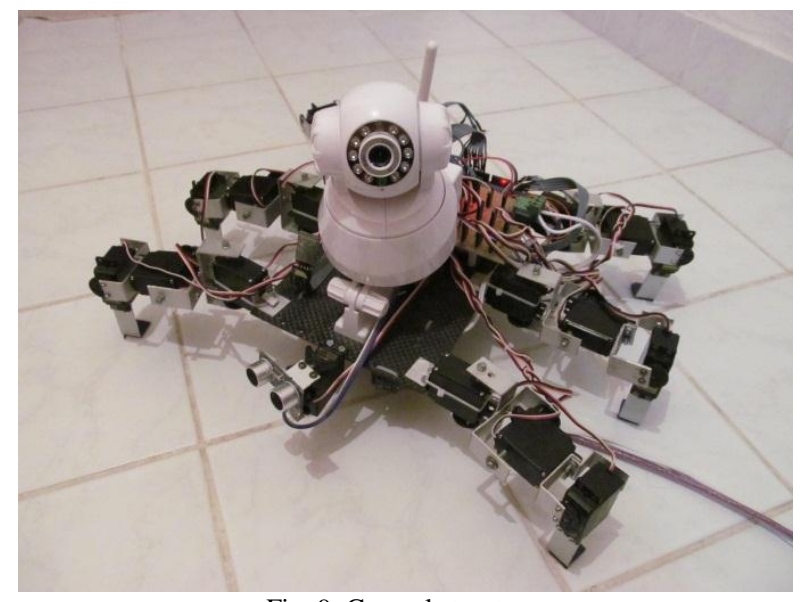

Fig. 9. General structure.

\section{CONTROL OF TKSPIDER1 ROBOT}

TKSPIDER1's control unit is based on technology of Arduino. Each leg was commanded by microcontroller [8]. See for more detailed information about Arduino in [9].

PWM signal from outputs of Arduino board is transmitted over connector board to servo motors. Totally, robot has 19 actuators. 18 motors of them belong to legs and the rest for motion of ultrasonic sensor. The block diagram of the system can be expressed as shown in Fig. 10.

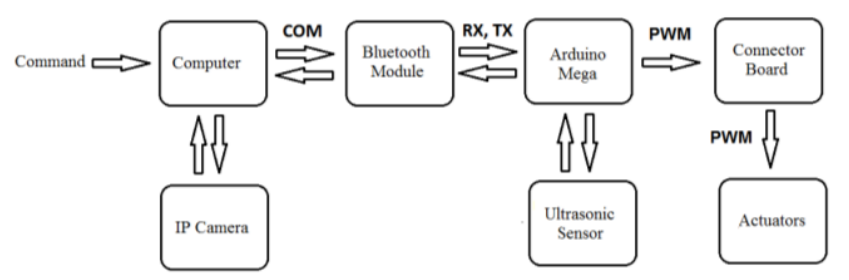

Fig. 10. The block diagram of TKSPIDER1.

The locomotion is provided by entering commands into the computer. The command was transmitted over bluetooth link to microcontroller, and then the mechanism runs. In addition, area which robot presents can be tracked through received image from camera in real time. This camera has completely separate data bus in control of robot as IP camera (see Fig.11).

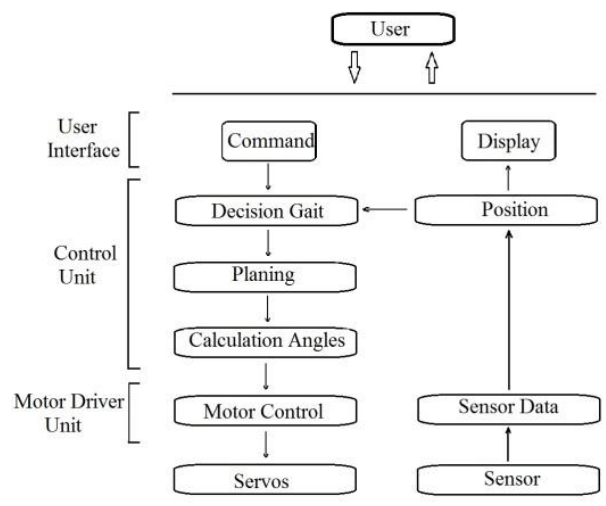

Fig. 11. The control architecture of TKSPIDER1.

\section{AlgORITHMS OF LOCOMOTION AND EXPERIMENTAL RESULTS}

Four different gaits coded for TKSPIDER1 robot. These algorithms has been developed according to changing environmental conditions which are explorer, tripod, biped and wave gaits. With those robot walked to forward, reverse, right and left. Also leg coordination was suitable form to demanded any walking complications such as diagonal. The body and legs are schematically depicted as in Fig. 12 and Fig. 13

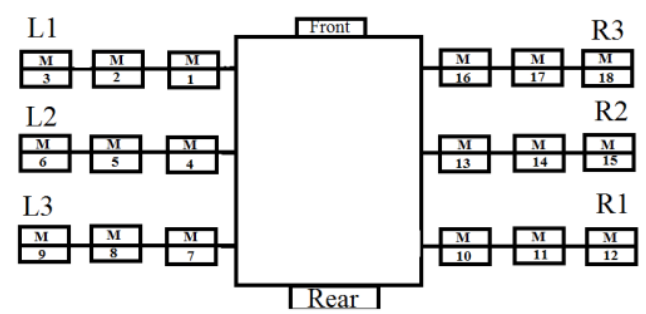

Fig. 12. TKSPIDER1 leg scheme.

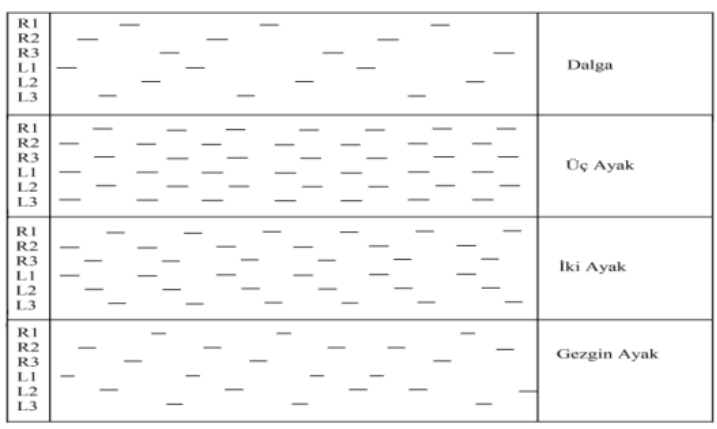

Fig. 13. Gait pattern of walking algorithms. Black short lines describe moves of TKSPIDER1. Wave gait where only one leg is in its swing phase at a time and five legs are in their stance phase. Tripod gait where a set of three legs cycle between swing and stance phases and are antiphase with the remaining three legs. Biped gait is similar to three step gait as respectively legs move to serial next states. Explorer gait where each leg is located repeatedly after motion of other leg.

\section{A. Wave}

Legs are moved to next phase consecutively, and main body is propelled simultaneously when locomotion of robot. The cycle is continue until next command (see Fig. 14).
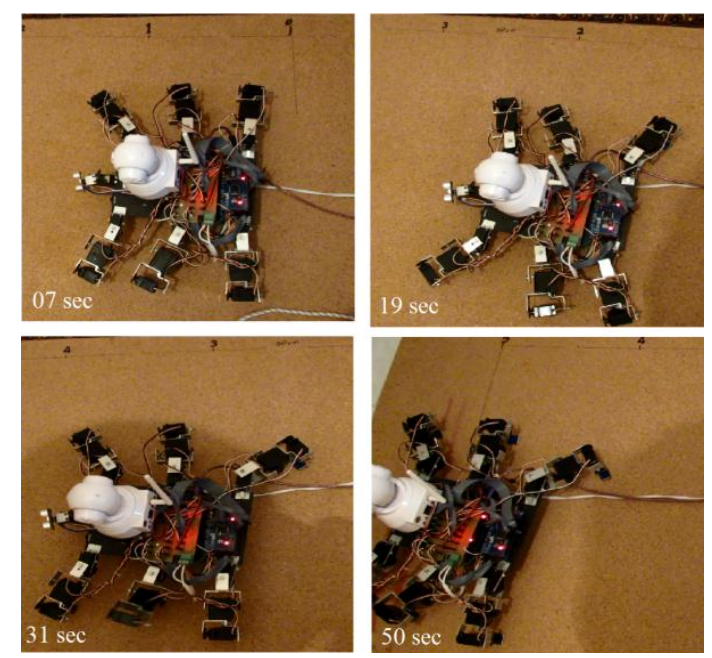

Fig. 14. Wave gait.

\section{B. Tripod}

All legs totally through double moves are located at next 
phase as three legs cycle between swing and stance phases. In this way, tripod gait is the fast and easy algorithm among built algorithms. Tripod has capacity that may be used in all terrains (see Fig. 15).
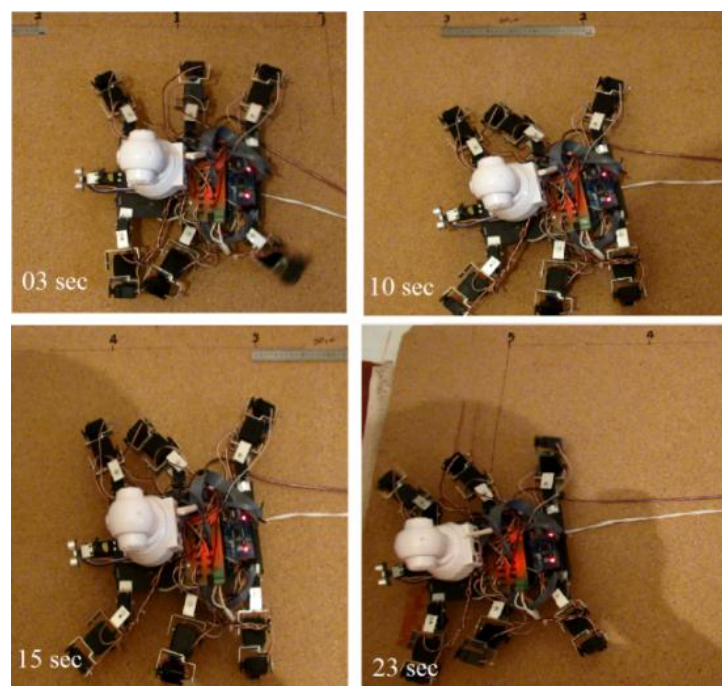

Fig. 15. Tripod gait.
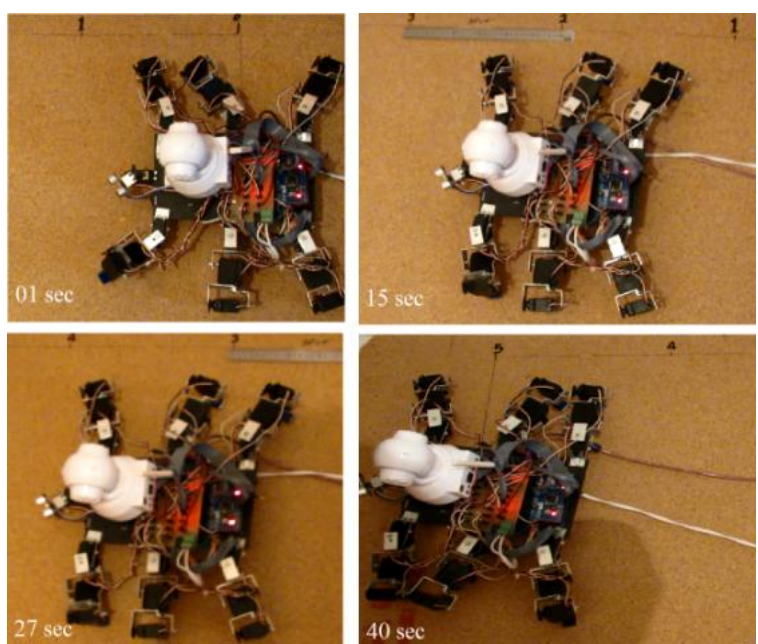

Fig. 16. Biped gait for TKSPIDER1.

\section{Biped}

Biped leg coordination is described as progressing of pair of legs. First moving of robot is occurred in three moves. When stance of any leg, other legs propel the body forward as seen from Fig. 16. The purpose of location of this algorithm in this section is providing more variety about gaits. In velocity status, biped gait is exist between tripod and explorer gait (see Fig. 16).

\section{Explorer Gait}

Explorer gait have more similarity with wave about running series of legs. Both of gaits are controlled via sequence motions. In this algorithm, robot walked more slowly and sensitive due to all legs moved respectively. At the same time, when the robot is progressed, always five legs propelled the body. Therefore this gait should be preferred in more rough terrains. Moving steps was expressed in Fig. 17 and shown in Fig. 18.

\section{E. Experimental Results}

TKSPIDER1 robot was tested with all walking algorithms on flat ground. Advantages and disadvantages in combinations of legs have been obtained by using experimental result.

When analyzed the results of test according to Table II, the velocity of tripod gait is the most fast as $0.065 \mathrm{~m} / \mathrm{sec}$. observation were carried out on wood flat material is clamped into place (see Table III). The purpose of this observation testing on flat ground is surveying the detection speed, the stability of motion and the leg coordination.

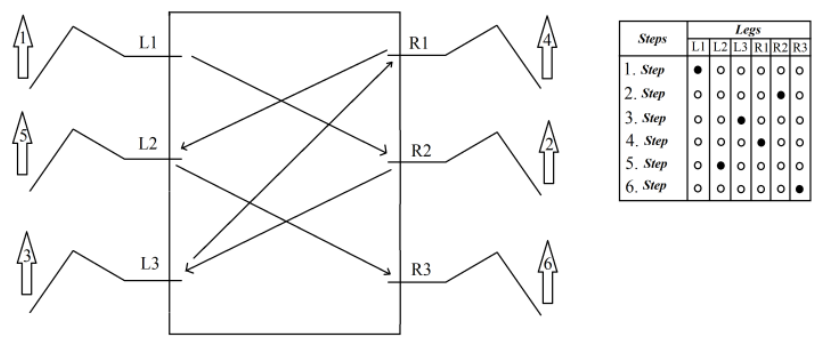

Fig. 17. Motion steps of explorer gait.
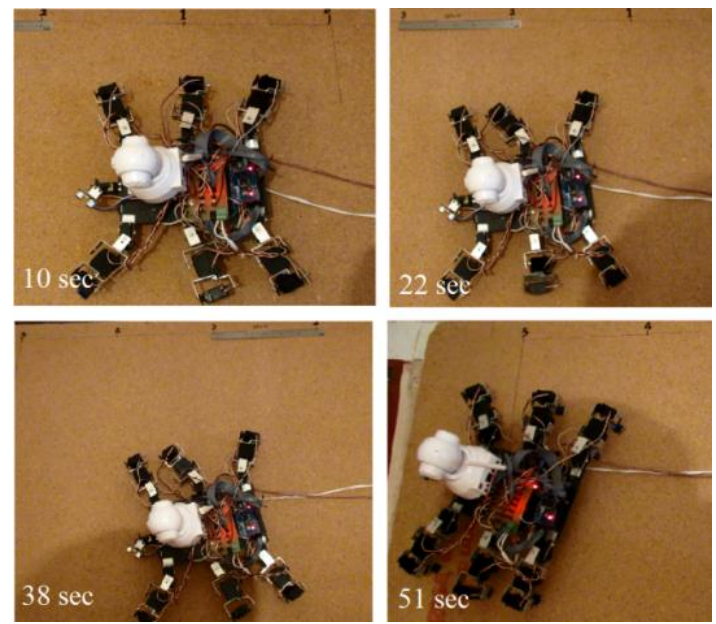

Fig. 18. According to result of tests, explorer gait was the slowest and sensitive to conditions of ground.

TABLE II: OBTAINED PARAMETERS ACCORDING TO WALKING ALGORITHMS

\begin{tabular}{|l|l|l|l|l|}
\hline \multirow{2}{*}{ Gaits } & \multicolumn{4}{|c|}{ Parameters } \\
\cline { 2 - 5 } & $\begin{array}{c}\text { Step Length } \\
\boldsymbol{m}\end{array}$ & $\begin{array}{c}\text { Distance } \\
\boldsymbol{m}\end{array}$ & $\begin{array}{c}\text { Time } \\
\text { sec }\end{array}$ & $\begin{array}{c}\text { Velocity } \\
\boldsymbol{m} / \text { sec }\end{array}$ \\
\hline Explorer & 0,08 & 1,50 & 51 & 0,029 \\
\hline Tripod & 0,06 & 1,50 & 23 & 0,065 \\
\hline Wave & 0,07 & 1,50 & 50 & 0,030 \\
\hline Biped & 0,14 & 1,50 & 40 & 0,038 \\
\hline
\end{tabular}

TABLE III: DOF OF LEG SEGMENTS RELATED TO GAITS

\begin{tabular}{|l|l|l|l|}
\hline \multirow{2}{*}{\multicolumn{1}{|c|}{ Gaits }} & \multicolumn{3}{c|}{ Leg Segments } \\
\cline { 2 - 4 } Explorer & Coxa degree & Femur degree & Tibia degree \\
\hline Tripod & 40 & 50 & 45 \\
\hline Wave & 60 & 50 & 40 \\
\hline Biped & 40 & 60 & 45 \\
\hline
\end{tabular}

\section{RESULTS AND RECOMMENDATIONS}

Mechanical structure and electronics equipment of search and rescue robots present differences in respect of aims of 
using. The robot should be able to move easily on application area and affected from physical barriers on minimum level. If used the remote controlling, this function should be fulfilled using suitable receiver-transmitter system.

TKSPIDER1 robot that designed under this project is developed both of flat grounds and rough terrains. To robot does not occupy larger field, for more extensive in branches of using fields and having feature that to use for various aims is designed. Bluetooth module was included to robot for communication from computer to mechanism and Arduino Mega board is used to remote control. Command was transmitted over the bluetooth link to robot. Records from IP camera that located on TKSPIDER1 may be transferred wirelessly to computer in real time.

The performed robot has structure can also be improved. First of all, mechanical components can be improved and in various states against to fall, crash and inversion preventions may be increased. In case of reversal, software and hardware that have running as reversal may be built for robot. As hardware, the most simple revision is using motors can be rotated 360 degree.

Except robot can be walk on six legs, when needed it, robot should be walked on just two or four legs. For walking on only rear legs, making a detailed study and computations on body, robot may be run as humanoid robots balancing the center of gravity of robot.

In flat terrain, for progressing of robot is faster, wheels should be added to system. Thence, when needed high velocity, robot will be continued through active wheels, and when needed legs will be run. For these improvements may be created in both of mechanical and software.

In the case of the defense mechanism of the robot, in records that taken from IP camera as detection of people, animal or needed algorithms should be processed images.

This six-legged robot developed as a rescue robot, is completely open to be developed, and also has feature that more comfortable building.

\section{ACKNOWLEDGMENT}

This work was supported in part by the Selcuk University. Authors are thankful to RAC-LAB (http://www.rac-lab.com/) for providing the trial version of their commercial software for this study.

\section{REFERENCES}

[1] U. Saranli, M. Buehler, and D. E. Koditschek, "Rhex-A simple and highly mobile hexapod robot," Int. J. Robot. Res., vol. 20, pp. 616-631, 2001.
[2] SIRVENT: Sistema reconfigurable para la navegación basada en visión de robots caminantes y rodantes en entornos naturales. [Online]. Available: http://www.iri.upc.edu/project/show/42.

[3] Robot insect 'Genghis'. [Online]. Available: http://www.sciencephoto.com/media/344230/view

[4] B. L. Luk, D. S. Cooke, S. Galt, A. A. Collie, and S. Chen, "Intelligent legged climbing service robot for remote maintenance applications in hazardous environments," Robotics and Autonomous Systems, vol. 53, pp. 142-152, 2005.

[5] K. Berns, V. Kepplin, W. Ilg, and R. Dillmann, "Experiments with a stereo camera head for the local navigation of LAURON III," Forschungszentrum Informatik Karlsruhe, Germany, 1993.

[6] O. Parlaktuna and E. Eroğlu, "Gezgin Robotlarda Ultrasonik Mesafe Algılayıcılarla Robot Davranışlarının Kontrolü ve Çevre Haritalama," Eskisehir Osmangazi Üniversitesi Müh. Mim. Fak. Dergisi, p. 87, 2007.

[7] K. F. Graff, "A History of Ultrasonics," in Physical Acoustics, vol. 15, W. P. Mason and R. N. Thurston, Eds, Academic Pres, 1981.

[8] R. D. Quinn and K. S. Espenschied, "Control of a Hexapod Robot Using a Biologically Inspired Neural Network," in Biological Neural Networks in Invertebrate Neuroethology and Robotics, R. D. Beer, R. E. Ritzmann, T. M. McKenna, Eds. Academic Press, New York, 1993 , pp. 365-382.

[9] M. Margolis, Arduino Cookbook, S. St. Laurent and B. Jepson, Eds. O’Reilly Media, Inc., 1005 Gravenstein Highway North.

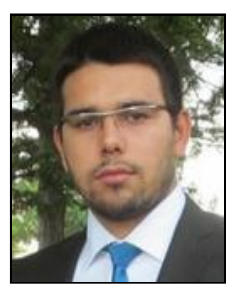

Tolga Karakurt received his B.Sc. degree in electrical-electronics engineering from the Selcuk University, (SU), Turkey, in 2014. He is currently a M.Sc. candidate at the Department of Electrical-Electronics Engineering from the Selcuk University. His research interests are machine learning algorithms, human-robot interaction and robotics.

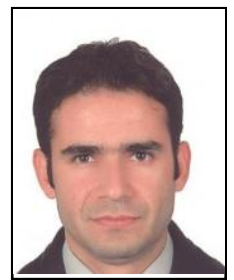

Akif Durdu has been an assistant professor with the Eletrical-Electronics Engineering Department at the Selcuk University (SU) since 2013. He earned a Ph.D. degree in eletrical-electronics engineering from the Middle East Technical University (METU), in 2012. He received his B.Sc. degree in eletrical-electronics engineering in 2001 at the Selcuk University. His research interests include mechatronic design, search $\&$ rescue robotics, robot manipulators, human-robot interaction, multi-robots networks and sensor networks. Dr. Durdu is teaching courses in control engineering, robotic and mechatronic systems.

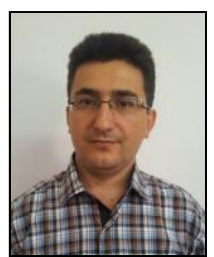

Nihat Yilmaz has been an associate professor with the Eletrical-Electronics Engineering Department at the Selcuk University (SU) since 2014. He earned a Ph.D. degree in eletrical-electronics engineering from the Selcuk University (SU), in 2005. He received his B.Sc. degree in eletrical-electronics engineering in 1996 at the Selcuk University. His research interests include mechatronic design, search \& rescue robotics, robot manipulators, human-robot interaction. Dr. Yilmaz is teaching courses in microcontrollers, robotic vision and advenced digital systems. 